\title{
THIOL GROUPS OF SOYBEAN GALLUS SUCCINYL CoA SYNTHETASE
}

\author{
EVA A. WIDER de XIFRA ANd ALCIRA M. DEL C. BATLLE \\ Departamento de Quimica Biológica, Facultad de Ciencias Exactas y Naturales, Ciudad \\ Universitaria, Buenos Aires, Argentina
}

(Received 15 May I973)

\begin{abstract}
I. The reaction between 5,5'-dithio-bis-(2-nitrobenzoic acid) (DTNB) and the SH groups of soybean callus succinyl-CoA synthetase has been investigated. At $\mathrm{pH} 8 \cdot 6$ and $25^{\circ} \mathrm{C}$, four SH groups are titrable with DTNB in the native enzyme. No additional thiol groups have been revealed after unfolding of the protein with $8 \mathrm{M}$ urea.

2. The loss of enzymatic activity paralleled the decrease in the number of free $\mathrm{SH}$ groups. As with $p$-mercuribenzoate and other mercurials, reaction with DTNB also resulted in dissociation of the enzyme into subunits.
\end{abstract}

IN an earlier communication, this laboratory has reported the purification of succinylCoA synthetase from soybean callus tissue (Wider de Xifra \& Tigier, 1971). These studies revealed that the soybean callus enzyme has a molecular weight of approximately 160,000 and that it is inactivated by several sulphydryl reagents, stressing the importance of thiol groups for the catalytic activity of succinyl-CoA synthetase. In addition, with the purified enzyme classic Michaelis-Menten kinetics were not always followed (Wider de Xifra \& Tigier, 1970, I97I); therefore, the presence of subunits seems probable. In fact, dissociation of this enzyme by mercurials and other reagents has been already reported (Ramaley, Bridger, Moyer \& Boyer, 1967; Grinnell, Stollar \& Nishimura, I969; Grinnell \& Nishimura, 1970; Leitzmann, Wu \& Boyer, I970).

No clear evidence about the existence of disulphides bridges at the active site has been obtained and not much information is available as to the groups involved in the enzymatic reaction. Some evidence exists suggesting the presence of vicinal thiol groups (Wider de Xifra \& Batlle, unpublished results).

The availability of purified soybean callus succinyl-CoA synthetase in relatively good quantity, has opened the way to the study of the content and behaviour of its sulphydryl groups.

In the present work 5,5'-dithio-bis-(2nitrobenzoic acid) (DTNB), has been used to study the number of thiol groups of soybean callus succinyl-CoA synthetase, the reactivity of these groups in the presence and absence of denaturing agents has been examined and the relationship of these groups to the catalytic activity of the enzyme has been investigated. It is known that DTNB offers the advantage over some other sulphydryl reagents of reacting rather specifically with thiol groups and the reaction can be easily measured.

\section{MATERIALS AND METHODS}

All chemicals used were p.a. graded and purchased from Sigma Chem. Co., if not stated otherwise. Sephadex was from Pharmacia Co., Uppsala, and DTNB was from Aldrich Chemical Co. The purity of DTNB was checked spectrophotometrically (Ellman, 1958).

Photometric measurements were carried out in a Beckman D.U. or a Beckman, D.B. spectrophotometer, with recorder.

Succinyl-CoA synthetase was purified and its activity was measured as previously described (Wider de Xifra \& Tigier, 1971). A molecular weight of 160,000 was used for calculations.

The experiments on inactivation were carried out as follows: solutions containing the enzyme were first incubated in a cuvette at $25^{\circ} \mathrm{C}$ for approximately 10 minutes, this permitted temperature equilibration; the DTNB was then added, 
the incubations were continued for the intervals indicated and terminated by withdrawal of a o.I-ml. sample which was assayed for activity.
Control experiments, performed with DTNB, indicated that at the final concentration used, this reagent did not affect the colour development of
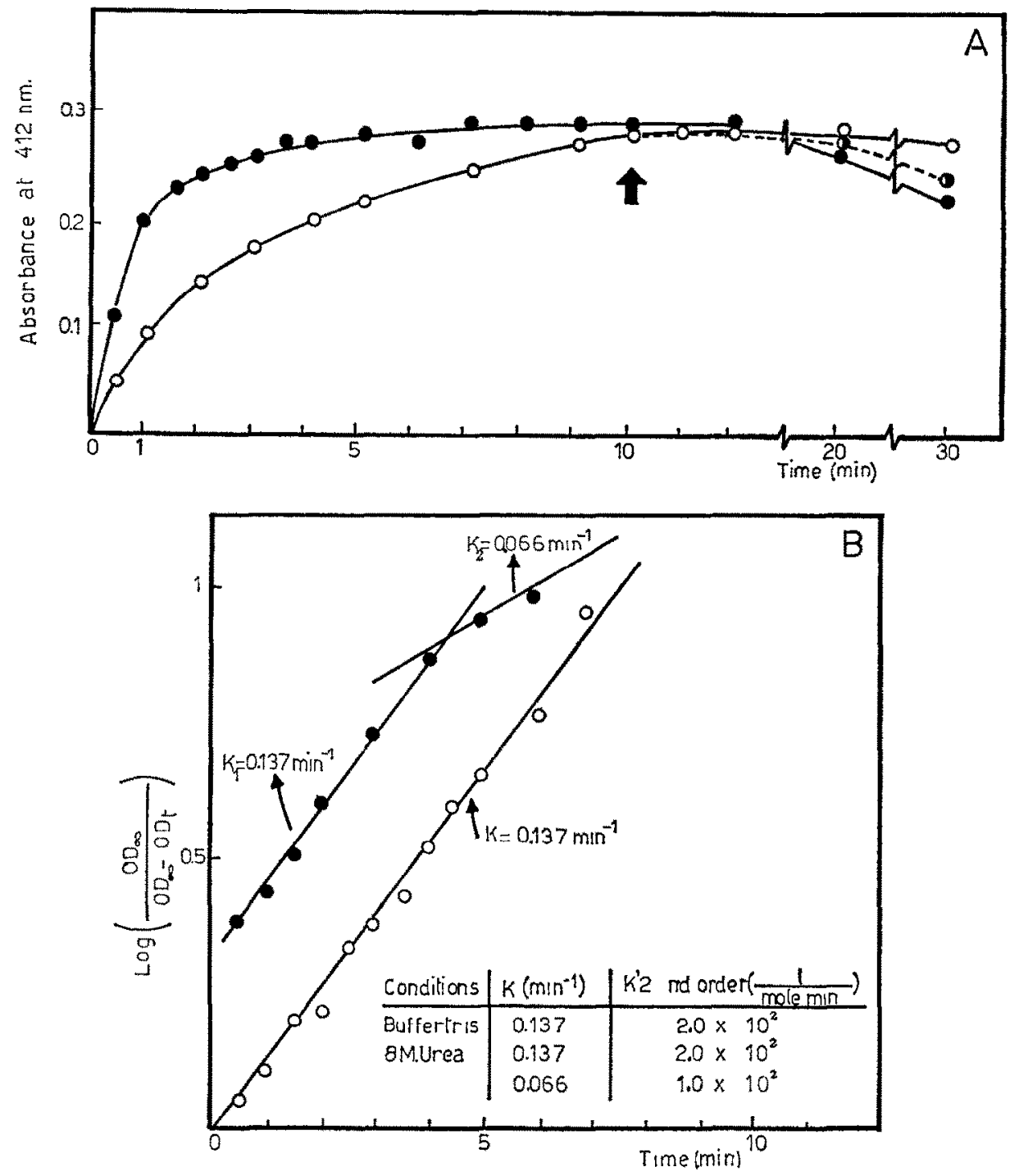

Fig. 1.- Rates of reaction between the sulphydryl groups of soybean callus succinyl-CoA synthetase and DTNB in the presence and absence of $8 \mathrm{M}$ urea. A, Product (5-thio-2-nitrobenzoate) formation followed spectrophotometrically at $412 \mathrm{~nm}$, as a function of time (in minutes). Initial reaction mixture in $0.05 \mathrm{M}$ Tris-HCl buffer, $\mathrm{pH} 8.6: 6.6 \times 10^{-4} \mathrm{M}, 3.87 \times 10^{-6} \mathrm{M}$ enzyme, and $\mathrm{I} \times 10^{-3} \mathrm{M}$ EDTA. Other components also present were: 0 , none; $0,8 \mathrm{M}$ urea. After 10 minutes of incubation to one reaction mixture without urea, $8 \mathrm{M}$ urea was added (divided black/white symbols), as indicated by the arrow, and the course of reaction was followed as shown by the dashed lines; B, Pseudo-first-order plots for reactions with DTNB. Data from A plotted in first-order fashion in terms of $\log _{10}\left[E_{\infty} / E_{\infty}-E_{t}\right]$ versus time (in minutes). $E_{\infty}$ is the maximum observed extinctions value at $412 \mathrm{~nm}$. and $E_{\mathrm{t}}$ is its value measured at time $t$. In the presence of a large excess of DTNB, the calculated pseudo-first-order $k$ could be recalculated in terms of a second-order rate constant, $k^{\prime}$, obtained by dividing $k$ values by the initial DTNB concentration; $k^{\prime}=k / \mathrm{DTNB}$. Calculated kinetic data are given in the insert. 
the succinyl hydroxamate reaction employed to estimate product formation.

Protein was determined by the method of Lowry, Rosebrough, Farr \& Randall (1951).

Normally reactive sulphydryl groups were measured by using DTNB, according to Ellman (1959). The disulphide exchange between this reagent and SH groups yields reduced DTNB, which has an intense yellow colour when ionized at alkaline $\mathrm{pH}$. The increase in absorbance at $412 \mathrm{~nm}$., resulting from the liberation of the thionitrobenzoate ion at $\mathrm{pH} 8.6$, was measured and the molar extinction coefficient of 13,600 mole ${ }^{-1} . \mathrm{cm}^{-1}$ was used to calculate the thiol content. All values were corrected by appropriate blanks. For the measurement of total sulphydryl content by DTNB, a denaturant such as $8 \mathrm{M}$ urea was also included in the incubation mixture. The temperature employed for all titrations was $25^{\circ} \mathrm{C}$.

Gel filtration columns were prepared as already described (Batlle, Benson \& Rimington, 1965; Batlle, 1967). Their void volume was determined with Blue Dextran 2000 and they were calibrated for molecular weight estimations with cytochrome a, myoglobin, ovalbumin, serum albumin and highly purified succinyl-CoA synthetase. All elutions from the columns were always carried out with the equilibration buffer.

\section{RESULTS}

Kinetics and Extent of Reaction with DTNB

FIG. I A shows the time course for the reaction of soybean callus succinyl-CoA synthetase with DTNB in the presence and absence of $8 \mathrm{M}$ urea. It is seen from the figure that, in the absence of denaturant, the spectrophotometric end-point (close to four sulphydryl groups per mole) is met at about to minutes, and no additional SH groups are exposed if the total reaction time is extended much beyond the periods indicated in FIG. IA. The rate of increase becomes constant, remaining the same for approximately $10-20$ minutes, showing that the reaction has reached completion; it then falls slightly.

It is also seen that the first three sulphydryl groups react very rapidly ( 4 minutes), after which follows a period of 6 minutes where the absorbance rises more slowly and only one more $\mathrm{SH}$ group reacts.

In the presence of $8 \mathrm{M}$ urea a very rapid reaction with DTNB is observed, two sulphydryl groups react in the first minute and a total of four groups react within 4 minutes; after 20-30 minutes the absorbance begins to fall, very probably as a result of auto-oxidation of the thionitrophenilate ion. As is also shown in Fig. I A, after four $\mathrm{SH}$ groups had been titrated with DTNB and $8 \mathrm{M}$ urea was added to the incubation mixture containing the enzyme and DTNB, as expected, no change in absorbance was observed. Therefore, no additional sulphydryl groups could react with DTNB in the presence of $8 \mathrm{M}$ urea.

In the presence of a large excess of DTNB the reaction appears to follow pseudo-firstorder kinetics (Fta. I B) with a constant $k$ of about $0.137 \mathrm{~min}^{-1}$; however, in the presence of $8 \mathrm{M}$ urea, the plot of the pseudo-first-order rate was biphasic; the $k_{1}$ value was the same as that obtained in the absence of denaturant, while a constant $k_{2}$ of about $0.066 \mathrm{~min}^{-1}$, half the $k_{1}$ value was obtained; we can not easily explain this result.

The calculated second order constant $k_{2}^{\prime}$ of $1 \cdot 0 \times 10^{2} 1 . \cdot$ mole $^{-1} \cdot \mathrm{min}^{-1}$ was again half the value of $2.0 \times 10^{2}$ for the four reactive sulphydryl groups of the native enzyme.

The kinetics of the substitution of soybean callus succinyl-CoA synthetase were followed

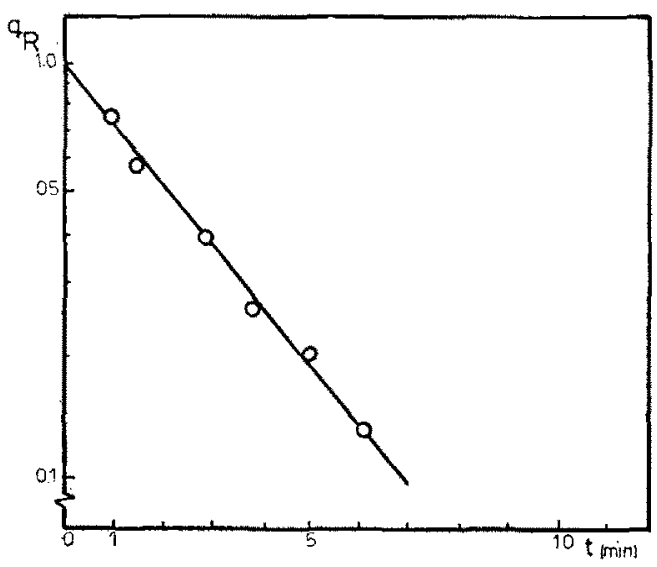

Fic. 2.-Kinetics of substitution by DTNB. The relative concentration of intact $\mathrm{SH}$ groups as a function of time is calculated; $\log q_{\mathrm{R}}=f(t)$, where $q_{\mathrm{R}}=\left(Z_{\infty}-Z\right) / Z_{\infty}, Z$ is the number of $\mathrm{SH}$ groups per mole substituted at any time $t$, and $Z_{\infty}=4^{\circ}$. Initial reaction mixture, in $0.05 \mathrm{M}$ Tris-HCl buffer, pH $8.6: 6.6 \times 10^{-4} \mathrm{M}$ DTNB, $4.2 \times 10^{-6} \mathrm{M}$ enzyme, and $\mathrm{I} \times 10^{-3} \mathrm{M}$ EDTA. 


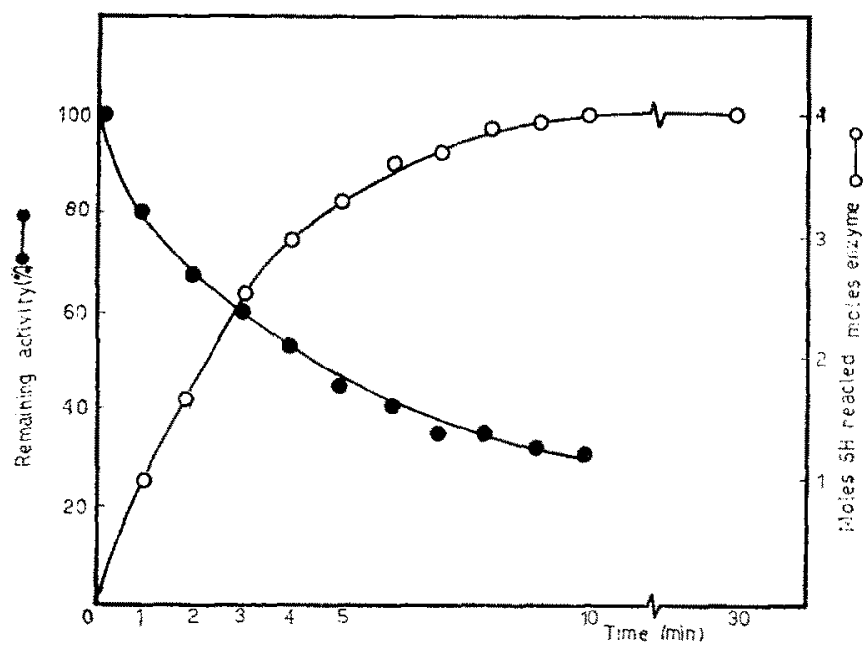

Frc. 3-Inactivation of soybean callus succinyl-CoA synthetase by DTNB. Solutions were prepared in cuvettes containing the following, in $0.05 \mathrm{M}$ Tris-HCl buffer, $\mathrm{pH} 8.6: 6.6 \times 10^{-4} \mathrm{M}$ DTNB and $4.5 \times 10^{-6} \mathrm{M}$ enzyme. The reaction with DTNB was followed by reading absorbance at $412 \mathrm{~nm}$. and expressed in terms of $\mathrm{SH}$ groups reacted per mole of enzyme, and the inactivation was by withdrawal at the indicated times of $0.1 \mathrm{ml}$. samples for assay of enzymatic activity, as described in Methods.

, Changes in enzyme activity; $\mathrm{O}$, moles of $\mathrm{SH}$ groups reacted per mole of enzyme.

spectrophotometrically, recording, as stated, the increase of the absorbance at $412 \mathrm{~nm}$. as a function of time (Fra. IA). From these curves the residual fraction $q_{R}=\left(Z_{\infty}-Z\right) / Z_{\infty}$, i.e., the relative concentration of intact $\mathrm{SH}$ groups, was calculated, where $z$ is the number of $\mathrm{SH}$ groups per mole of enzyme, substituted at any time $t$. In Fro. 2, the first-order plots obtained are shown, suggesting that the reaction with DTNB is pseudofirst-order with respect to the four SH groups. Thus, the reaction appears to be independent of the concentration of unreacted $\mathrm{SH}$ groups.

It was also found that the rate of reaction increased linearly with DTNB concentration (over a concentration range from $5 \times 10^{-5} \mathrm{M}$ to $\left.6.6 \times 10^{-4} \mathrm{M}\right)$, also indicative that the reaction is pseudo-first-order with respect to the concentration of DTNB. The overall reaction is, therefore, a second-order reaction.

It was observed that the profile of the reactivity curve of the thiol groups was not dependent on the type of buffer used, when the reaction with DTNB was carried out in Tris- $\mathrm{HCl}$ or phosphate buffers.

\section{InACTIVATION BY DTNB}

The time course of the inactivation was followed in the succinyl-CoA synthetase coupled test by taking small portions from the incubation mixture at different times ( $t)$ and measuring the enzymic activity $A$, will high saturating substrate concentrations. Fro. 3 shows the effect of DTNB on catalytic activity, which decreased rapidly with time; the rate of decrease of free $\mathrm{SH}$ groups was approximately the same as the rate of decrease on activity. However, after DTNB had reacted with all the four $\mathrm{SH}$ groups per mole 25-30 per cent of activity was still retained.

In FIG. 4 are shown the kinetics of inactivation by DTNB when the concentration of the disulphide is in considerable excess over that of the enzyme; pseudo-first-order kinetics are observed. The apparent firstorder rate constant for inactivation, was also found to be proportional to the concentration of DTNB.

The kinetics of the inactivation and the substitution by DTNB can be correlated by plotting the fractional inhibition, $i=\left(A_{0}-A\right) / A_{0}$ versus the number of substituted $\mathrm{SH}$ groups 
per mole of enzyme; $i=f(\mathcal{Z})$ for the corresponding times of incubation. These plots are given in FIG. 5; if the activity is measured under optimal conditions, 20 per cent of inactivation occurs when one $\mathrm{SH}$ group is substituted, it is also seen that the plot is biphasic and the rate of reaction of the fourth $\mathrm{SH}$ group is slower than that of the first three groups.

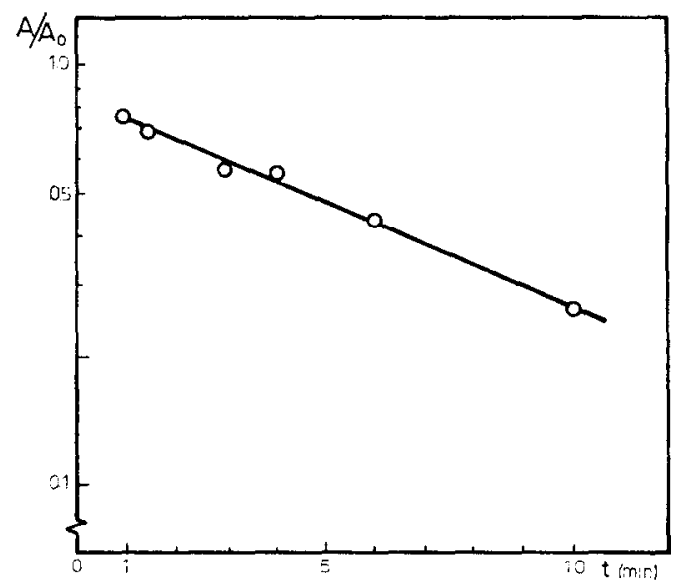

Fig. 4.--Kinetics of inactivation by DTNB as a function of time: $\log A / A_{0}=f(t)$. Enzyme inactivation was measured as described in Fig. 3 . $A$, Enzyme activity measured at any time $t$; $A_{0}$, activity of the enzyme at zero time, that is, immediately before adding DTNB. Incubation mixture, in $0.05 \mathrm{M}$ Tris-Hal buffer, $\mathrm{pH} 8.6$ : $6.6 \times 10^{-4} \mathrm{M}$ DTNB and $4.85 \times 10^{-6} \mathrm{M}$ enzyme.

In some experinents, when 1-3 mM mercaptoethanol was added to solutions of partially active succinyl-CoA synthetase from which excess DTNB has been removed by gel filtration, an increase in enzymic activity was noted; for instance, an enzyme of 40 per cent residual activity was restored to 80 per cent of its original activity after incubation with mercaptoethanol for 30 minutes.

Inactivation by DTNB was the result of a specific reaction rather than generalized denaturation, since native enzyme incubated under the same conditions but in the absence of DTNB remains fully functional.

\section{Ehelit un Muleciulak Weight}

The molecular weight of soybean callus succinyl-CoA synthetase is altered by treat- ment with DTNB, as determined by gel filtration on Sephadex G-75 and G-I5O. In these experiments the enzyme, after Io minutes' incubation with DTNB, was applied to calibrated columns. Using this technique it was possible to separate subunits of molecular weight of about 80,000 from the heavy molecular weight component ( 160,000 ). When the enzyme was incubated with

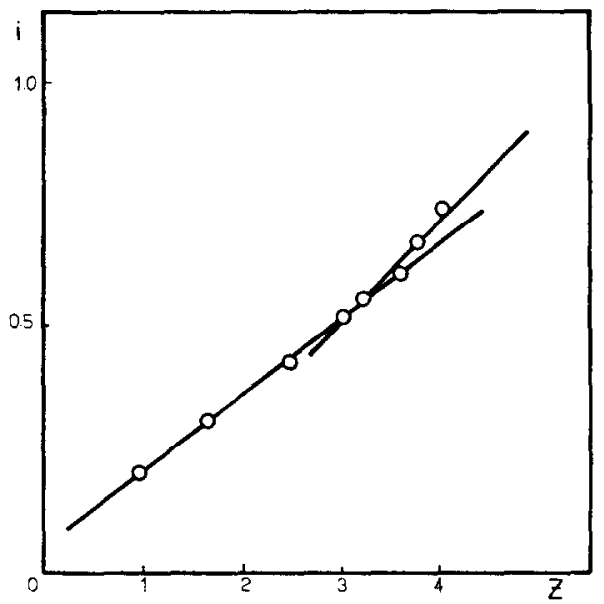

Fic. 5.-Correlation of the inactivation of succinyl-CoA synthetase and its substitution by DTNB. Fractional inhibition $i=\left(A_{0}-A\right) / A_{0}$ is plotted against the number of substituted $\mathrm{SH}$ groups per mole: $i=f(Z)$ for the corresponding times of incubation. Enzyme activities were measured as described in Fig. 3. Symbols $A$ and $Z$ are given in Figs. 2, 4 .

DTNB, $8 \mathrm{M}$ urea and I $\mathrm{mM}$ mercaptoethanol, almost the same picture emerged; only in the presence of 1 per cent sodium dodecyl sulphate, some evidence was obtained of further dissociation into subunits of molecular weight of about 40,000 ; so far attempts to dissociate the enzyme completely into subunits of low molecular weight have failed, and a significant aggregation tendency has been noted. Nevertheless, it is clear that the reaction with DTNB is accompanied by dissociation of the enzyme, which can be reversed by addition of reducing agents and may also account for the loss of enzymatic activity. These findings are now under investigation.

It is, perhaps, interesting to add that 
incubation of soybcan callus succinyl-CoA synthetase in the presence of $4 \mathrm{M}$ and $8 \mathrm{M}$ urea reduces activity of the enzyme to 62 and 4 I per cent respectively; that is, even in the presence of $8 \mathrm{M}$ urea, about 40 per cent of the enzymic activity was retained.

\section{CONGLUSIONS}

The results presented here indicate that the soybean callus succinyl-CoA synthetase possesses four SH groups after titration with DTNB, either in the absence or presence of the denaturant $8 \mathrm{M}$ urea. It has been stated that steric hindrance plays the most important role with respect to reactivity of the $\mathrm{SH}$ groups towards D'INB in proteins. The rather bulky DTNB molecule requires a certain amount of space in the proximity of the SH group in order to react, this being possible if the SH group is located at or near the surface of the protein molecule. Based on this reasoning, our results would suggest that all the SH groups of soybean callus succinyl-CoA synthetase are located on the surface of the protein and are readily and almost equally available for reaction with DTNB; no additional thiol groups have been revealed after unfolding the protein with $8 \mathrm{M}$ urea. Alternatively, as with $p$-mercuribenzoate (Grinnell \& Nishimura, 1970), DTNB seems to cause dissociation of the enzyme into subunits; therefore, it could also be possible that once the first $\mathrm{SH}$ group has reacted with DTNB the molecule might dissociate, thereby rapidly exposing the remaining $\mathrm{SH}$ groups.

Although, as stated above, the four $\mathrm{SH}$ groups seem to be equally reactive toward DTNB, some evidence obtained indicates that there could be a slight difference between the first three and the fourth SH group; but these results are difficult to interpret.

Loss of enzymatic activity was found to parallel the decrease in free SH groups; however, after blocking all the four titrable $\mathrm{SH}$ groups of soybean callus succinyl-CoA synthetase, about $25^{-} 3^{\circ}$ per cent of the activity remained, suggesting that the four thiol groups are responsible for maintaining 70 per cent of the activity. They are probably not within the active site, nevertheless, they have some control over it; thereforc, the existence of a sulphydryl group or more at the catalytic site of soybean callus succinylCoA synthetase remains unestablished.

The experiments reported here do not provide an answer to the question of whether soybean callus succinyl-CoA synthetase possesses any disulphide linkages and this possibility can not unambiguously be eliminated, although preliminary data would indicate that the enzyme contains no such bonds.

On the basis of these results, one could tentatively speculate, that the soybean callus succinyl-CoA synthetase of 160 ,000 of molecular weight, might consist of at least two and possibly four subunits of approximately equal size; assuming that they could have identical composition, the presence of one SH group per subunit can be envisaged. However, some preliminary results suggest the presence of vicinal thiol groups in succinyl-CoA synthetase, therefore the possibility also exists that the soybean callus enzyme is composed of at least two different species of subunits (Bridger, 1971), four SH groups being in only two of them; that is, two SH groups per subunit, a situation analogous to the existence of phosphorylated and non-phosphorylated subunits (Leitzmann et al., 1970).

\section{Acknowt.FngFiments}

A. M. del C. Batlle holds the post of Scientific Researcher in the Consejo Nacional de Investigaciones Cientificas y Técnicas, Buenos Aires, Argentina (C.N.I.C.T.). Part of this work was supported by grants from the C.N.I.C.T. and from the University of Buenos Aires. It forms part of the Thesis submitted by E. A. Wider de Xifra for the degree of Ph.D. to the University of Buenos Aires.

\section{REFERENCES}

Batlle, A. M. DEL C. (1967), 'Estimation of molecular weights of protcins by Bio-Gel P Gel filtration ', 7. Chromat, , 28, 82-88.

Batlle, A. M. del C., Benson, A., \& Rimington, C. $(1965)$, 'Purification and properties of coproporphyrinogenase', Biochem. $7 ., 97,73$ I-740. 
Bridger, W. A. (I97 I), 'Evidence for two types of subunits in succinyl CoA synthetase', Biochem. Biophys. Res. Commun., 42, 948-952.

EllmaN, G. (1958), 'A colorimetric method for determining low concentrations of mercaptans ", Archs. Biochem. Biophys., 74, 443-448.

Ellman, G. (1959), 'Tissue sulfhydryl groups ', Archs. Biochem. Biophys., 82, 70-78.

Grinneli, F. L. \& Nishimura, J. S. (1970), "The inactivation and dissociation of $E$. coli succinyl CoA synthetase by sulfhydryl reagents', Binchim. Biophys. Acta, 212, 150-157.

Grinnell, F. L., Stollar, B. D., \& Nishimura, J. S. (1969), "Reversible disaggregation of E. coli succinyl CoA synthetase", Biochim. Biophys. Acta, I85, 47 I-474.

Leitzmann, C., Wu, J. Y., \& Boyer, P. D. (I97o), 'Subunits, composition and related properties of succinyl CoA synthetase', Biochemistry, 9, $233^{8-2346 .}$

Lowry, O. H., Rosebrovgh, N. J., Farr, A. L., \& Randali, R. J. (I95I), "Protein measure- ment with the Folin phenol reagent', 7. Biol. Chem., r93, 265-275.

Ramalex, R. F., Bridger, W. A., Moyer, R. W., \& Boyer, P. D. $(1967)$, "The preparation properties and reactions of succinyl CoA synthetase and its phosphorylated form , 7. Biol. Chem., 242, $4287-4298$.

Wider de Xifra, E. A., \& Trgier, H. A. (1970), -Properties and regulatory effect on tetrapyrrole biosynthesis of succinyl CoA synthetase isolated from soybean callus system', FEBS Letters, 9, 30-32.

Wider de Xifra, E. A., \& Tigier, H. A. (I971), - Porphyrin biosynthesis in soybean callus tissue. VIII. Isolation, purification and general properties of succinyl CoA synthetase', Enzymologia, 4r, 21 7-231.

Key Word Index: Succinyl-CoA synthetase, soybean callus tissue, 5,5'-dithio-bis-(2-nitrobenzoic acid), thiol groups, enzyme inactivation, kinetics, molecular weight changes, subunits. 